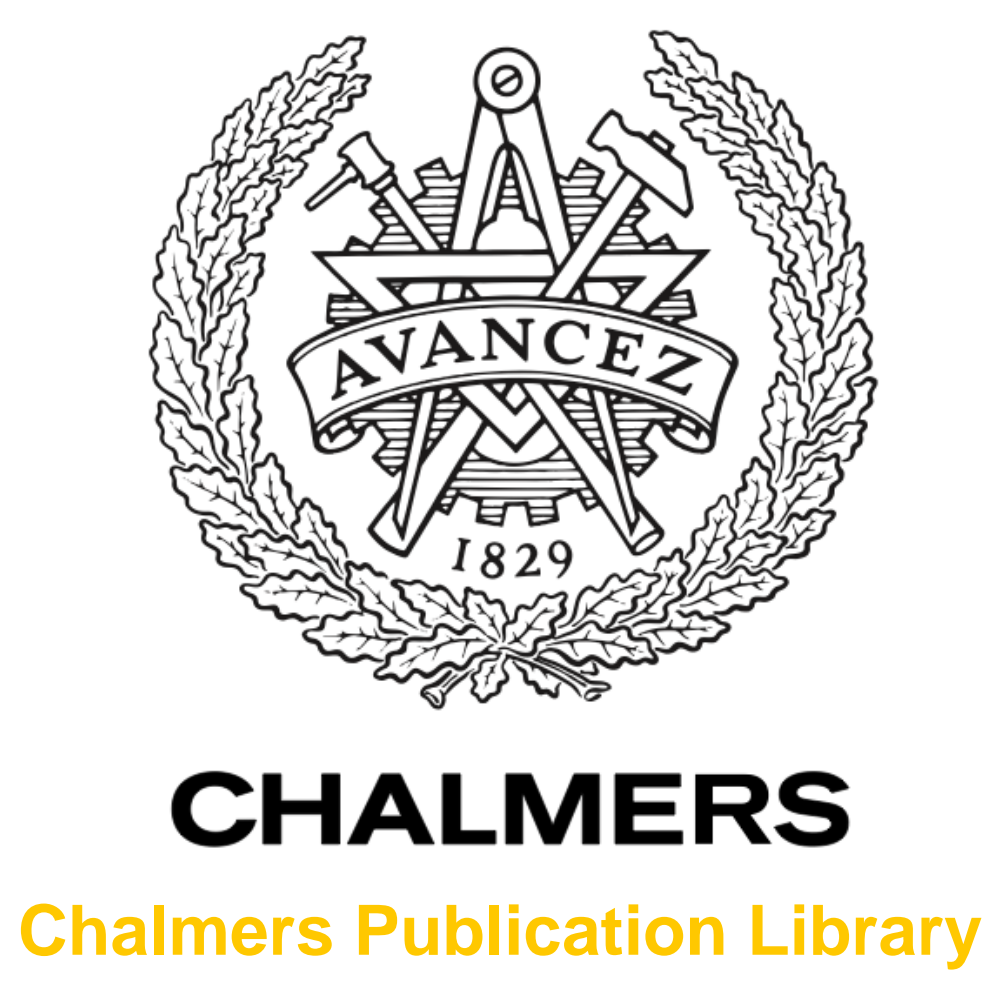

\title{
Hydrodynamic modelling and forecasting of microbial water quality in a drinking water source
}

This document has been downloaded from Chalmers Publication Library $(\mathrm{CPL})$. It is the author's version of a work that was accepted for publication in:

Journal of Water Supply: Research and Technology - Aqua (ISSN: 0003-7214)

Citation for the published paper:

Sokolova, E. ; Pettersson, T. ; Bergstedt, O. (2014) "Hydrodynamic modelling and forecasting of microbial water quality in a drinking water source". Journal of Water Supply: Research and Technology - Aqua, vol. 63(3), pp. 189-199.

Downloaded from: http://publications.lib.chalmers.se/publication/197302

Notice: Changes introduced as a result of publishing processes such as copy-editing and formatting may not be reflected in this document. For a definitive version of this work, please refer to the published source. Please note that access to the published version might require a subscription. 


\section{Hydrodynamic modelling and forecasting of microbial water quality in a}

\section{2 drinking water source}

3 Short title: Hydrodynamic modelling and forecasting of microbial water quality

4

5

Ekaterina Sokolova $^{\mathrm{a}, *}$, Thomas J.R. Pettersson ${ }^{\mathrm{a}}$ and Olof Bergstedt ${ }^{\mathrm{a}, \mathrm{b}}$

${ }^{a}$ Department of Civil and Environmental Engineering, Water Environment Technology, Chalmers University of Technology, SE-412 96 Gothenburg, Sweden.

*Corresponding author. Tel. +46 31 7721929, Fax. +46 31 7722128, E-mail address:

ekaterina.sokolova@chalmers.se

${ }^{\mathrm{b}}$ City of Gothenburg, Box 123, SE-424 23 Angered, Sweden.

\section{Abstract}

Faecal contamination often enters drinking water sources through emergency discharges, which occur as a result of technical malfunctions or a hydraulic overload of the sewer system during periods of heavy rain. In October - November 2012, several emergency discharges entered Lake Rådasjön - a drinking water source for Gothenburg, Sweden. To describe and forecast the influence of these emergency discharges on the microbial water quality, the spread of $E$. coli within the lake was simulated using a three-dimensional hydrodynamic model. The model was run for a period of four months using the observed data, and for a period of nine days using meteorological forecast data. The modelling results showed how much every contamination source contributed to the total $E$. coli 
concentrations at the water intakes. The agreement between the modelling results and the measured concentrations was satisfactory. The results of this study led to the decision to use the lake for drinking water production. This study demonstrated that the proposed modelling approach can be used to provide short-term forecasts of the microbial water quality in drinking water sources.

Key words: E. coli; faecal contamination; lake; MIKE 3 FM; sewer overflows; water quality modelling.

\section{Introduction}

The faecal contamination of drinking water sources can pose health risks for consumers. Faecal contamination often enters drinking water sources through emergency wastewater discharges during sewer overflow events, which occur mainly due to a hydraulic overload of the sewer network during periods of heavy rain or due to technical malfunctions. The emergency wastewater discharges may increase the levels of faecal contamination in raw water used for drinking water production.

In order to ensure that the drinking water treatment processes are sufficient to manage the increased levels of faecal contamination in the raw water, it is necessary to describe the influence of the wastewater discharges on the microbial water quality at the intake of a drinking water treatment plant. However, regular monitoring of the raw water quality may not be sufficient to capture the rapid changes in the faecal contamination levels. To complement the monitoring, hydrodynamic modelling can be used to simulate the spread of faecal contamination within the water source. For example, hydrodynamic modelling studies of microbial water quality were performed by Thupaki et al. (2010) on a freshwater lake, Liu and Huang (2012) on an estuary and by Chan et al. (2013) on 
marine beaches. Moreover, hydrodynamic modelling was also used to provide a forecast regarding the microbial water quality at bathing sites (Chan et al. 2013).

Lake Rådasjön is a drinking water source for the cities of Gothenburg and Mölndal in Sweden. Between 1 October and 3 November 2012 several emergency wastewater discharges into the drinking water source Lake Rådasjön occurred; these discharges were caused by hydraulic overloads and, on one occasion, by a power failure. The goal of this study was to implement an existing hydrodynamic model of the lake to assess and forecast the influence of these wastewater discharges on the microbial water quality at the raw water intakes. A three-dimensional hydrodynamic model of Lake Rådasjön (Sokolova et al. 2012a, Sokolova et al. 2013) was used to simulate the spread of the faecal contamination from the emergency overflows and other contamination sources within the lake. In this study, we show how a hydrodynamic model can be used to describe and to forecast the water quality impacts of extreme weather-related events. The novelty of this study lies in suggesting hydrodynamic modelling as a method to forecast the microbial water quality in drinking water sources.

\section{Methods}

\section{Study area}

Lake Rådasjön is located on the west coast of Sweden. The surface area of the lake is approximately $2.0 \mathrm{~km}^{2}$ and its catchment comprises an area of $268 \mathrm{~km}^{2}$. The maximum water depth is $24 \mathrm{~m}$ and the main inflow into the lake is the river Mölndalsån (Figure 1). The water flow in the river Mölndalsån varies from 1 to $20 \mathrm{~m}^{3} / \mathrm{s}$ and the average water flow is approximately $4 \mathrm{~m}^{3} / \mathrm{s}$. The raw water intakes 
for the cities of Gothenburg and Mölndal are located in the north-western part of the lake at depths of 8 and $15 \mathrm{~m}$, respectively (Figure 1).

Lake Rådasjön serves as the main water source for the city of Mölndal (60 000 consumers, annual withdrawal of water 5 million $\mathrm{m}^{3}$ ) and as one of the reserve water sources for the city of Gothenburg (500 000 consumers, annual withdrawal of water 5 million $\mathrm{m}^{3}$ ). The city of Mölndal has a reserve surface water source that could provide enough water for approximately one week. For the city of Gothenburg, the main drinking water source is the river Göta älv. However, the water intake in the river is closed for up to one third of the time, often due to suspected high levels of faecal contamination (Åström et al. 2007). The reserve water sources for the city of Gothenburg could provide drinking water for approximately three weeks. Water from Lake Rådasjön is also regularly to complement the river water.

There are no longer any national raw water quality standards in Sweden. The drinking water treatment plants supplied via this lake are operated according to the following arbitrary guidelines regarding the $E$. coli concentration in the raw water: $3-10 \mathrm{No} / 100 \mathrm{~mL}-$ increased need for microbial barrier efficiency and $>10 \mathrm{No} / 100 \mathrm{~mL}$ - severely increased need for barrier efficiency. There is no upper limit regarding the microbial raw water quality, the decisions are based on the aim to use the best available raw water for drinking water production.

Lake Rådasjön is subject to contamination from various faecal sources, which were identified in earlier studies of this lake (Sokolova et al. 2012a, b). The faecal contamination enters the lake through emergency wastewater discharges from the pumping station Pixbo Päls (location PS, Figure 1) and from the pumping station located near the stream Vällbäcken (location V, Figure 1). These 
emergency wastewater discharges occur several times a year, due to hydraulic overloads or technical failures within the sewer network. The faecal contamination in the lake can also originate from the on-site sewage treatment systems (hereafter referred to as on-site systems), which were designed for sludge removal. These on-site systems do not meet legal requirements regarding treatment performance and provide little to no microbial reduction. The effluent from these on-site systems is continuously released into a stream that enters the lake close to the raw water intakes (location OS, Figure 1). Moreover, faecal contamination can enter the lake through the inflow from the river Mölndalsån (Figure 1), which transports contamination from various sources, mainly emergency sewer overflows and on-site systems, located in its upstream catchment area.

In addition, the faecal contamination from a cattle grazing area located to the east of the lake and an urban area located to the north-east of the lake could enter the lake with the surface runoff (pasture and urban areas in Figure 1). In an earlier modelling study of the lake (Sokolova 2011), the contributions from the cattle grazing area and the urban area to the total E. coli concentrations at the water intake were estimated to be approximately 2 and $1 \log _{10}$ units less than from the river Mölndalsån, respectively. According to the results of another study (Sokolova et al. 2012b), the contribution from the cattle grazing area to the concentrations of Bacteroidales genetic markers at the water intake was approximately $1 \log _{10}$ unit less compared to the contributions from the on-site systems and from the Pixbo Päls pumping station. Furthermore, in a study on the pathogen concentrations in this lake (Sokolova et al. 2012a), it was found that the contributions from the cattle grazing area and the urban area to the Cryptosporidium concentrations at the water intake were approximately 1 and $3 \log _{10}$ units less than from the Pixbo Päls pumping station, respectively. In summary, based on the results of the earlier studies of this lake, we have concluded that the contribution from these nonpoint sources is generally much smaller than from the other identified 
contamination sources. Therefore, we do not consider the contribution from these nonpoint sources in this article.

\section{Model implementation}

To simulate the water flows in Lake Rådasjön, the three-dimensional time-dependent hydrodynamic model MIKE 3 FM (DHI 2011a) was used. In order to simulate the fate and transport of the faecal contamination in Lake Rådasjön, the microbial water quality model ECO Lab (DHI 2011b) was coupled to the hydrodynamic model of the lake.

The model was set up to study the influence of the emergency sewer overflows that occurred between 1 October and 3 November 2012 (Table 1) on the microbial water quality at the raw water intakes in Lake Rådasjön. The first simulation was performed on 12 and 13 November, shortly after the overflow events, in order to enable timely decisions regarding the drinking water production. The model was run for a period in the past (1 September - 11 November 2012) using observed hydrometeorological data, and a forecast period (12 - 20 November 2012) using forecast data (Figure 2). Later, the simulation was repeated for 12 - 20 November 2012 using observed data, and was extended to include the period 21 November - 31 December 2012 (Figure 2).

\section{Hydrodynamic model}

The hydrodynamic model for this lake was developed in earlier studies (Sokolova et al. 2012a, Sokolova et al. 2013). In brief, the MIKE 3 FM model is based on the numerical solution of threedimensional incompressible Reynolds averaged Navier-Stokes equations using Boussinesq and hydrostatic assumptions (DHI 2011a). The model consists of continuity, momentum, temperature, 
and density equations, and is closed using a turbulent closure scheme. Horizontal and vertical eddy viscosities were modelled using the Smagorinsky and k-epsilon formulations, respectively.

The modelling domain was approximated with prisms (triangles in the horizontal plane), using a flexible mesh approach, i.e. the size and shape of the mesh elements in the horizontal plane could vary to describe the complex geometry of the modelling domain. The mesh consisted of 611 nodes and 1015 elements. The length of the triangles' sides varied from approximately 40 to $90 \mathrm{~m}$, and was adjusted to describe the coastline and bathymetry. Vertically, the lake was approximated with 37 layers of varying thickness (from $0.5 \mathrm{~m}$ in the thermocline zone to $3 \mathrm{~m}$ at the bottom). For more information on the spatial discretisation of the modelling domain and model calibration the reader is referred to Sokolova et al. (2013).

The model was set up to account for the hydrometeorological conditions and to simulate heat exchange between the atmosphere and the lake. The data regarding air temperature, relative humidity, wind speed and direction were obtained from Weather Underground (Weather Underground 2013) for the meteorological station of Landvetter, located approximately 10 $\mathrm{km}$ from Lake Rådasjön. The observed and forecast data were available with 0.5 and 3 hour temporal resolution, respectively. The clearness coefficient (cloud coverage) was specified as an average of the observed data for the period 2007 - 2011 (data provided by the Swedish Meteorological and Hydrological Institute, SMHI). Precipitation on the lake surface was not accounted for in the model. The temperature distribution in the lake at the beginning of the simulation on 1 September 2012 was assumed to be the same as on 1 September 2011. Therefore, the initial conditions regarding the temperature distribution in the lake were specified using the modelling output for the year 2011, obtained in an earlier study (Sokolova et al. 2013). The temperature on the open boundaries was described as zero gradients. The lake was assumed to be covered by ice starting from 30 November 
2012. In the model, the heat exchange and the wind stress were excluded for the areas covered by ice.

The conditions on the inflow and outflow boundaries were specified using time series ( 1 day temporal resolution) of the flow in the river Mölndalsån and the water level in Lake Stensjön, respectively. The data regarding flow variations in the river Mölndalsån were obtained from the SMHI (SMHI 2013); the data on the water level variations in Lake Stensjön were obtained from Mölndals Kvarnby - the association that controls and regulates the water flow in the water system of the river Mölndalsån (Mölndals Kvarnby 2013). For the forecast period, the flow in the river Mölndalsån and the water level Lake Stensjön were specified as constant values; the values used were the average values for November 2007 - 2011. The initial conditions in the lake were defined by the constant surface elevation; the flow velocity was set to zero. The land boundary was defined by zero normal velocity.

\section{Microbial water quality model}

The microbial water quality model ECO Lab uses the flow fields from the hydrodynamic model to calculate the concentrations of faecal indicators in the lake. The fate and transport of the faecal contamination were simulated using $E$. coli bacteria as a faecal indicator. In the ECO Lab model, the inactivation of the E. coli in the lake due to temperature and sunlight was described by Equation 1: 
where $t$ is the time; $C$ is the $E$. coli concentration; $k_{0}\left(1 /\right.$ day) is the decay rate at $20^{\circ} \mathrm{C}$ for a salinity of 0 $\%$ and darkness; $\theta_{s}$ is the salinity coefficient for the decay rate; $S a l(\%)$ is the salinity; $\theta_{1}$ is the light coefficient; Int $\left(\mathrm{kW} / \mathrm{m}^{2}\right)$ is the light intensity integrated over depth; $\theta_{\mathrm{T}}$ is the temperature coefficient for the decay rate; $\operatorname{Temp}\left({ }^{\circ} \mathrm{C}\right)$ is the water temperature.

The decay of E. coli and other faecal indicators in Lake Rådasjön was studied earlier during outdoor microcosm trials, which were performed in different seasons (March, August and November 2010) in light exposure and darkness (Sokolova et al. 2012b). Since no statistically significant differences between the persistence of $E$. coli in light and dark incubations were identified (paired samples t-test, p $>0.05)$, the light coefficient $\left(\theta_{1}\right)$ in Eq. 1 was set to 1 . The salinity coefficient $\left(\theta_{s}\right)$ in Eq. 1 was also set to 1 , as Lake Rådasjön is a fresh water lake. The temperature $\left(\theta_{T}\right)$ and the decay rate $\left(k_{0}\right)$ coefficients for $E$. coli were set to 1.04 and 0.2 , respectively. To distinguish between the influences of different contamination sources on the water quality at the intake, the contamination spread from each source was modelled separately.

Several emergency discharges were registered within the sewer network located in the vicinity of Lake Rådasjön during the study period (Table 1). As a result of these emergency discharges, untreated wastewater entered Lake Rådasjön from the pumping station Pixbo Päls and from the pumping station located near the stream Vällbäcken. The discharges on 1 October, 3 October and 3 November 2012 occurred due to a hydraulic overload of the sewer system, as a result of heavy rains, while the discharges on 25 October 2012 were caused by an extensive power failure. It can be assumed that, due to dilution by stormwater, the $E$. coli concentration in the discharged wastewater was lower when the discharges were caused by heavy rain than by a power failure. 
To account for the influence of the on-site systems on the microbial water quality in Lake Rådasjön, it was assumed that these systems provide no microbial reduction and discharge untreated wastewater. The discharge of wastewater from the on-site systems was calculated based on the estimation that there are 36 people connected to these systems and that the average water consumption is $200 \mathrm{~L} /$ person/day.

The $E$. coli concentrations in the discharges from the contamination sources were assigned using data on the E. coli concentrations in untreated wastewater from the Pixbo Päls pumping station measured under dry weather conditions (four measurements). The data collected under dry weather conditions were used in order to provide a worst-case scenario and to prevent possible underestimation due to uncertainties regarding the degree of wastewater dilution during wet weather conditions. It was assumed that the $E$. coli concentration in the untreated wastewater was $2 \times 10^{6} \mathrm{No} / 100 \mathrm{~mL}$, which was the median value. The E. coli concentration in the emergency discharges on 25 October 2012 was assumed to be higher than on the other occasions, since these discharges were caused by a power failure and not by a hydraulic overload. Therefore, to account for the worst-case scenario, it was assumed that the E. coli concentration in the emergency discharges on 25 October 2012 was $6 \times 10^{6} \mathrm{No} / 100 \mathrm{~mL}$, which was the maximum measured concentration.

The concentrations of $E$. coli bacteria in the river Mölndalsån were measured every week during September - December 2012 (18 measurements). The E. coli concentrations in the river Mölndalsån during this period varied between 6 and $370 \mathrm{No} / 100 \mathrm{~mL}$, and the median and average concentrations were 31 and $84 \mathrm{No} / 100 \mathrm{~mL}$, respectively. It was assumed that the concentrations of $E$. coli in the river Mölndalsån varied linearly between the measured values. For the forecast period, the concentration of $E$. coli in the river was the average value for November $2009-2011$. 
233 Based on the aforementioned assumptions and data, the $E$. coli load from different sources to Lake Rådasjön was calculated (Figure 2).

The $E$. coli concentrations at the water intakes were monitored by the cities of Gothenburg and

\section{Results and Discussion}

\section{Modelling microbial water quality}

The spread of the faecal contamination in Lake Rådasjön during September - December 2012 was simulated using the developed hydrodynamic model. The modelling results showed how much every considered contamination source contributed to the total E. coli concentrations at the water intakes

(Figure 3). According to the modelling results, the highest peaks at the water intakes were caused by the river Mölndalsån and the emergency discharges caused by a power failure (Figure 3 and 4). These discharges occurred on 25 October 2012 and were transported to the lake by the stream Vällbäcken.

247 The modelling results showed that, in this case study, the contribution from the emergency

248 discharges caused by heavy rainfalls was lower than the contribution from the other contamination 249 sources (Figure 3).

The contribution from the river Mölndalsån to the $E$. coli concentrations at the water intakes fluctuates over time (Figure 3), due to variations in the E. coli load (Figure 2) and in the hydrodynamic situation in the lake. After the contamination enters the lake with the water flow from the river 
Mölndalsån, it is mixed during the transport in the narrow and shallow part of the lake (Figure 5). The contaminant spread in the wide part of the lake is largely driven by wind (Figure 5).

Since the discharges from the pumping stations Pixbo Päls and Vällbäcken also enter the lake in its narrow part, the contaminant spread from these sources is similar to that from the river Mölndalsån. The discharge from the Vällbäcken pumping station caused high concentrations at the water intakes (Figure 3), mostly due to the assumption of high E. coli load during this event (Figure 2).

Since the $E$. coli load from the on-site systems was assumed to be constant (Figure 2), the fluctuations in the contribution from this source to the $E$. coli concentration at the intakes are only dependent on the hydrodynamic situation, which is largely driven by wind.

A comparison of the modelling results and the measured $E$. coli concentrations at the water intakes indicated that, taking into account the measurement uncertainties of the $E$. coli analyses (Köster et al. 2003), the agreement between the simulated and measured values was satisfactory (Figure 4). The model performance was quantified in a similar manner as by Chan et al. (2013): the correlation coefficient (R) and root-mean-square-error (RMSE) between decimal logarithms of the simulated and measured E. coli concentrations $\left(\log _{10}(E\right.$. coli $\left.)\right)$ were calculated. For the $8 \mathrm{~m}$ water intake, the model performance was $(N=13): R=0.64$ and RMSE $=0.42 \log _{10}(E$. coli $)$. For the $15 \mathrm{~m}$ water intake, the model performance was $(\mathrm{N}=17): \mathrm{R}=0.71$ and $\mathrm{RMSE}=0.47 \log _{10}(E$. coli $)$.

\section{The model described the peak in the E. coli concentrations observed in the end of October and the} low concentrations observed in December (Figure 4). However, on some occasions, the simulated 
concentrations were higher (up to approximately $1 \log _{10}$ unit) than the measured E. coli concentrations at the intakes, for example, in the first half of October (Figure 4). These high simulated concentrations of $E$. coli at the water intakes in the first half of October were caused by the river Mölndalsån (Figure 3), due to the high E. coli load from the river in the beginning of October (Figure 2). However, the E. coli load from the river was likely overestimated on this occasion, due to linear interpolation between the weekly measured concentrations (24 September: 17 No/100 mL; 1 October: 370 No/100 mL; 8 October: 12 No/100 mL).

The simulated $E$. coli concentrations at the intakes were linearly dependent on the input data regarding the E. coli load from the contamination sources. Therefore, the uncertainties in the modelling results originated (i) from the assumptions regarding the $E$. coli concentrations in the wastewater discharges, and (ii) from the linear interpolation between the weekly measured concentrations in the river Mölndalsån.

\section{Forecasting microbial water quality}

The hydrodynamic model was used to provide a forecast of the $E$. coli concentrations at the raw water intakes. For this purpose, the model was run for the period $12-20$ November 2012 using meteorological forecast data and the assumptions regarding the boundary conditions and the $E$. coli load (forecast run). Then, this simulation was repeated using the observed data as input for the model (hindcast run). The comparison of the results of both runs showed that the magnitude of the simulated concentrations was similar; but with some discrepancies in terms of temporal variations (Figure 6). For example, on 17 November 2012, the difference between the E. coli peaks at the water intakes predicted by the forecast and hindcast runs was less than $2 \mathrm{No} / 100 \mathrm{~mL}$ (Figure 6). However, for the forecast run, the predicted E. coli peaks occurred 11 and 10 hours earlier at the $8 \mathrm{~m}$ and $15 \mathrm{~m}$ 
water intakes, respectively, than for the hindcast run (Figure 6). The most prominent differences were observed for the simulated contribution from the on-site systems (Figure 7). This can be explained by the fact that the spread of contamination from the on-site systems was strongly dependent on the wind forcing; thus, the differences between the forecasted and observed meteorological data (Figure 8) were reflected in the modelling results. Some minor differences (up to $2 \mathrm{No} / 100 \mathrm{~mL}$ ) were also noticed for the simulated contribution from the river Mölndalsån (Figure 7); these differences originated from the differences in the underlying assumptions regarding the $E$. coli load from this source. No differences (less than $1 \mathrm{No} / 100 \mathrm{~mL}$ ) were observed for the simulated contributions from the emergency discharges.

The results of this study demonstrated that a hydrodynamic model can be used to simulate the raw water quality in a near real-time regime and to forecast the microbial water quality in a drinking water source. However, in order to utilise this modelling approach to facilitate everyday drinking water management, a better integration of the input data is needed. In the case of Lake Rådasjön, most of the required input data (observed and forecasted meteorological data, water flow in the river Mölndalsån and water level in Lake Stensjön) were available from different online sources. The data regarding the emergency discharges, the $E$. coli concentrations in the river Mölndalsån and at the water intakes were available through personal contact with the municipalities. However, preparation of the input data for the model was still a labour intensive and time consuming process. A solution could be to construct a unified database, in which the data are stored in a suitable format and regularly updated. This database could be used to generate input data for the model, which then could be run continuously and used to provide short-term forecasts of the $E$. coli concentrations at the water intakes. Nevertheless, careful and extensive validation of the model is of the utmost importance for the implementation of this modelling approach for drinking water management. 
According to long-term climate predictions, the intensity of precipitation events will increase (Olsson et al. 2009, Willems et al. 2012). Considering the current capacity of the sewer networks, this would lead to more frequent sewer overflow events. In this context, hydrodynamic modelling constitutes a suitable tool to describe and forecast the impact of these extreme weather events on the microbial water quality in drinking water sources.

\section{Outcomes for drinking water suppliers}

After the emergency overflow events that took place between 1 October and 3 November, on 10 November, the at-line monitoring equipment of the drinking water supplier in Gothenburg detected an increase in the E. coli concentrations at the raw water intakes in Lake Rådasjön. Consequently, the Gothenburg raw water intake was closed. However, on 13 November, when provided with the modelling results, which showed that the peak in the $E$. coli concentrations had already passed (Figure 4), the water supplier decided to re-open the water intake. This example shows that such modelling results can provide helpful information for drinking water suppliers and decision makers. For more examples of the practical outcomes from the modelling studies of Lake Rådasjön, the reader is referred to Sokolova et al. (2013).

\section{Conclusions}

The hydrodynamic model was successfully used to provide an assessment and forecast of the influence of emergency sewer overflows and of other sources on the faecal contamination levels at the water intakes. The comparison of the modelling results with the measured $E$. coli concentrations at the water intakes showed satisfactory agreement. The modelling results provided helpful decision support data for the drinking water suppliers. 
350 It was demonstrated that the proposed modelling approach can be used to provide short-term

351 forecasts of the microbial water quality in a drinking water source. Such forecasts are of particular

352 importance in the context of the predicted increase of rainfall intensity and, consequently, the

353 expected increase in frequency of emergency sewer overflows. A better system for collection and

354 integration of the necessary input data for the model is suggested as the next step towards the

355 implementation of this tool on a regular basis. This modelling approach can be used to facilitate

356 drinking water management and to address the health risks for consumers.

\section{Acknowledgements}

359 This research was funded by the Graduate School on Environment and Health (Forskarskolan Miljö

360 och Hälsa) of the Chalmers University of Technology and the University of Gothenburg, Sweden; the

361 Swedish Water and Wastewater Association (Svenskt Vatten); the EU project VISK (Interreg IV A

362 program). The authors are also grateful to: the Rådasjön project (SVU-project 29-122) management

363 group for valuable discussions; the city of Gothenburg, the city of Mölndal and the municipality of

364 Härryda for providing data for this research; DHI for providing the license for the MIKE software and

365 modelling support. 


\section{References}

Chan, S.N., Thoe, W. \& Lee, J.H.W. 2013 Real-time forecasting of Hong Kong beach water quality by 3D deterministic model. Water Res. 47(4), 1631-1647.

DHI 2011a MIKE21 \& MIKE 3 Flow Model FM Hydrodynamic Module, Short Description. DHI Water \& Environment, Horsholm. Available online at http://www.dhisoftware.com/ /media/Microsite MIKEbyDHI/Publications/PDF/Short\%20de scriptions/MIKE213 FM HD Short Description.ashx. Last accessed: June 2013.

DHI 2011b MIKE 21/3 Ecological Modelling: MIKE21/3 ECO Lab FM Short Description. DHI Water \& Environment, Horsholm. Available online at http://www.dhisoftware.com/ /media/Microsite MIKEbyDHI/Publications/PDF/Short\%20de scriptions/MIKE213 FM EL Short Description.ashx. Last accessed: June 2013.

Köster, W., Egli, T., Ashbolt, N., Botzenhart, K., Burlion, N., Endo, T., Grimont, P., Guillot, E., Mabilat, C., Newport, L., Niemi, M., Payment, P., Prescott, A., Renaud, P. \& Rust, A. 2003 Analytical methods for microbiological water quality testing. In: Assessing microbial safety of drinking water: Improving approaches and methods (Dufour, A., Snozzi, M., Koster, W., Bartram, J., Ronchi, E. and Fewtrell, L., ed.). Published on behalf of the World Health Organization and the Organisation for Economic Co-operation and Development by IWA Publishing, London, pp. 237-292.

Liu, W.C. \& Huang, W.C. 2012 Modeling the transport and distribution of fecal coliform in a tidal estuary. Sci. Total Environ. 431, 1-8.

Mölndals Kvarnby 2013 Water level in Lake Stensjön/Rådasjön. Available online at http://molndalskvarnby.se/. Last accessed: June 2013.

Olsson, J., Berggren, K., Olofsson, M. \& Viklander, M. 2009 Applying climate model precipitation scenarios for urban hydrological assessment: A case study in Kalmar City, Sweden. Atmos. Res. 92(3), 364-375.

SMHI 2013 Swedish Meteorological and Hydrological Institute: Vattenweb. Available online at http://vattenwebb.smhi.se/. Last accessed: June 2013.

Sokolova, E. 2011 Hydrodynamic and microbiological modelling of water quality in drinking water sources, Chalmers University of Technology, Gothenburg.

Sokolova, E., Åström, J., Pettersson, T.J.R., Bergstedt, O. \& Hermansson, M. 2012a Estimation of pathogen concentrations in a drinking water source using hydrodynamic modelling and microbial source tracking. J. Water Health 10(3), 358-370.

Sokolova, E., Åström, J., Pettersson, T.J.R., Bergstedt, O. \& Hermansson, M. 2012b Decay of Bacteroidales genetic markers in relation to traditional fecal indicators for water quality modeling of drinking water sources. Environ. Sci. Technol. 46(2), 892-900.

Sokolova, E., Pettersson, T.J.R., Bergstedt, O. \& Hermansson, M. 2013 Hydrodynamic modelling of the microbial water quality in a drinking water source as input for risk reduction management. $J$. Hydrol. 497(0), 15-23.

Thupaki, P., Phanikumar, M.S., Beletsky, D., Schwab, D.J., Nevers, M.B. \& Whitman, R.L. 2010 Budget analysis of Escherichia coli at a southern Lake Michigan Beach. Environ. Sci. Technol. 44(3), 1010-1016. 


\begin{tabular}{ccccr}
\hline Date & Time & Contamination source & Duration, hours & Volume, $\mathrm{m}^{3}$ \\
\hline 1 Oct 2012 & $16: 30-20: 00$ & Pixbo Päls & 3.50 & 30 \\
3 Oct 2012 & $21: 00-24: 00$ & Pixbo Päls & 3.00 & 30 \\
25 Oct 2012 & $16: 00-02: 00$ & Vällbäcken & 10.00 & 170 \\
25 Oct 2012 & $16: 00-02: 00$ & Pixbo Päls & 10.00 & 15 \\
3 Nov 2012 & $18: 30-20: 15$ & Pixbo Päls & 1.75 & 13 \\
\hline
\end{tabular}

Weather Underground 2013 Weather history and forecast for Gothenburg, Sweden. Available online at http://www.wunderground.com/. Last accessed: June 2013.

Willems, P., Arnbjerg-Nielsen, K., Olsson, J. \& Nguyen, V.T.V. 2012 Climate change impact assessment on urban rainfall extremes and urban drainage: Methods and shortcomings. Atmos. Res. 103(0), 106-118.

Åström, J., Pettersson, T.J.R. \& Stenström, T.A. 2007 Identification and management of microbial contaminations in a surface drinking water source. Journal of Water and Health 5(SUPPL. 1), 67-79.

\section{Table}

Table 1 Emergency sewer overflows into Lake Rådasjön (data provided by the Municipality of

Härryda)

420

421

422 


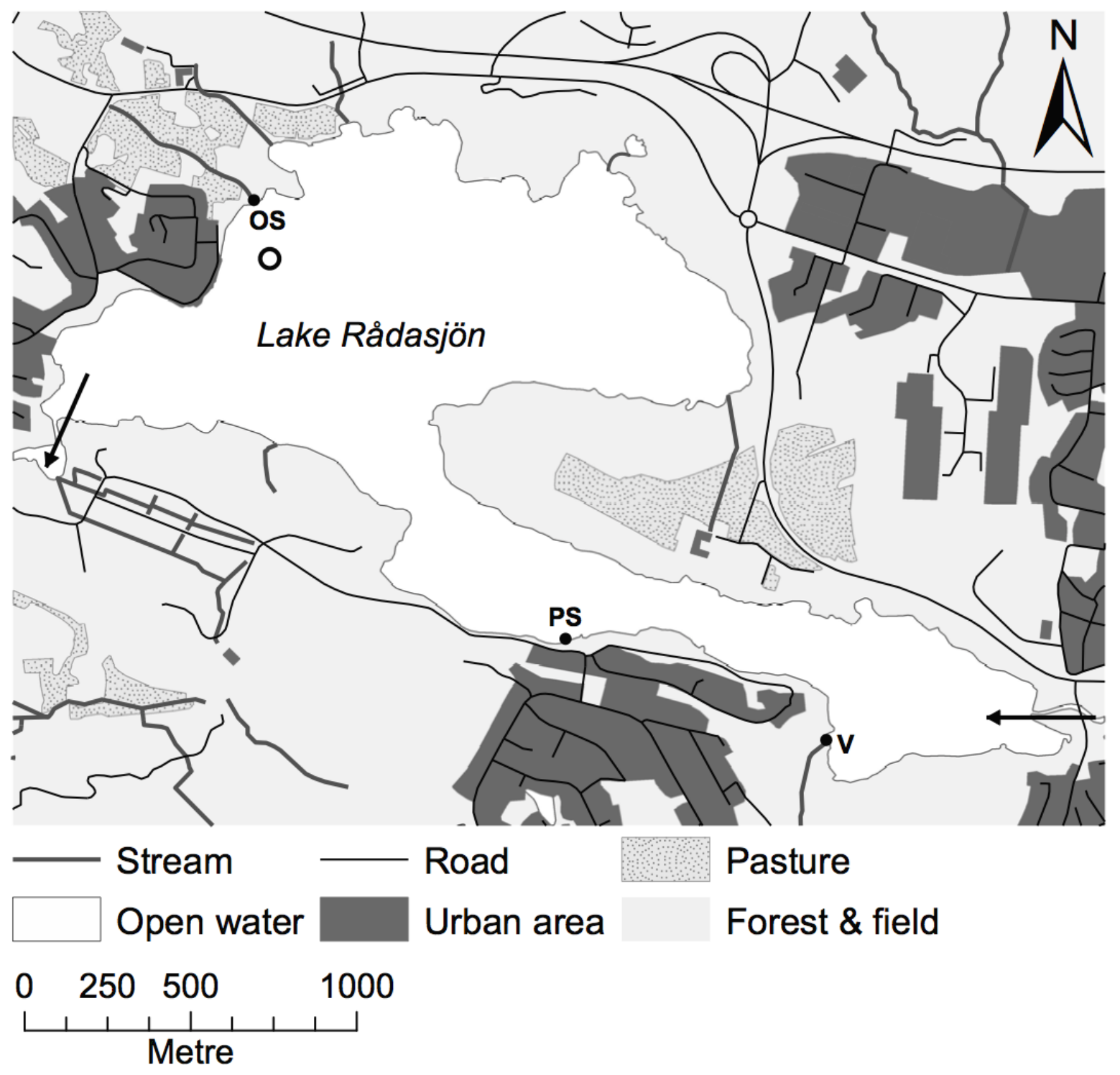

426 Figure 1 Map of Lake Rådasjön. Symbols: OS - the on-site sewage treatment systems, PS 427 the pumping station Pixbo Päls, V - the stream Vällbäcken that transports emergency 428 wastewater discharges. Black arrows represent the inflow to the lake from the river 429 Mölndalsån and the outflow from the lake to Lake Stensjön. The circle represents the location 430 of the raw water intakes. 


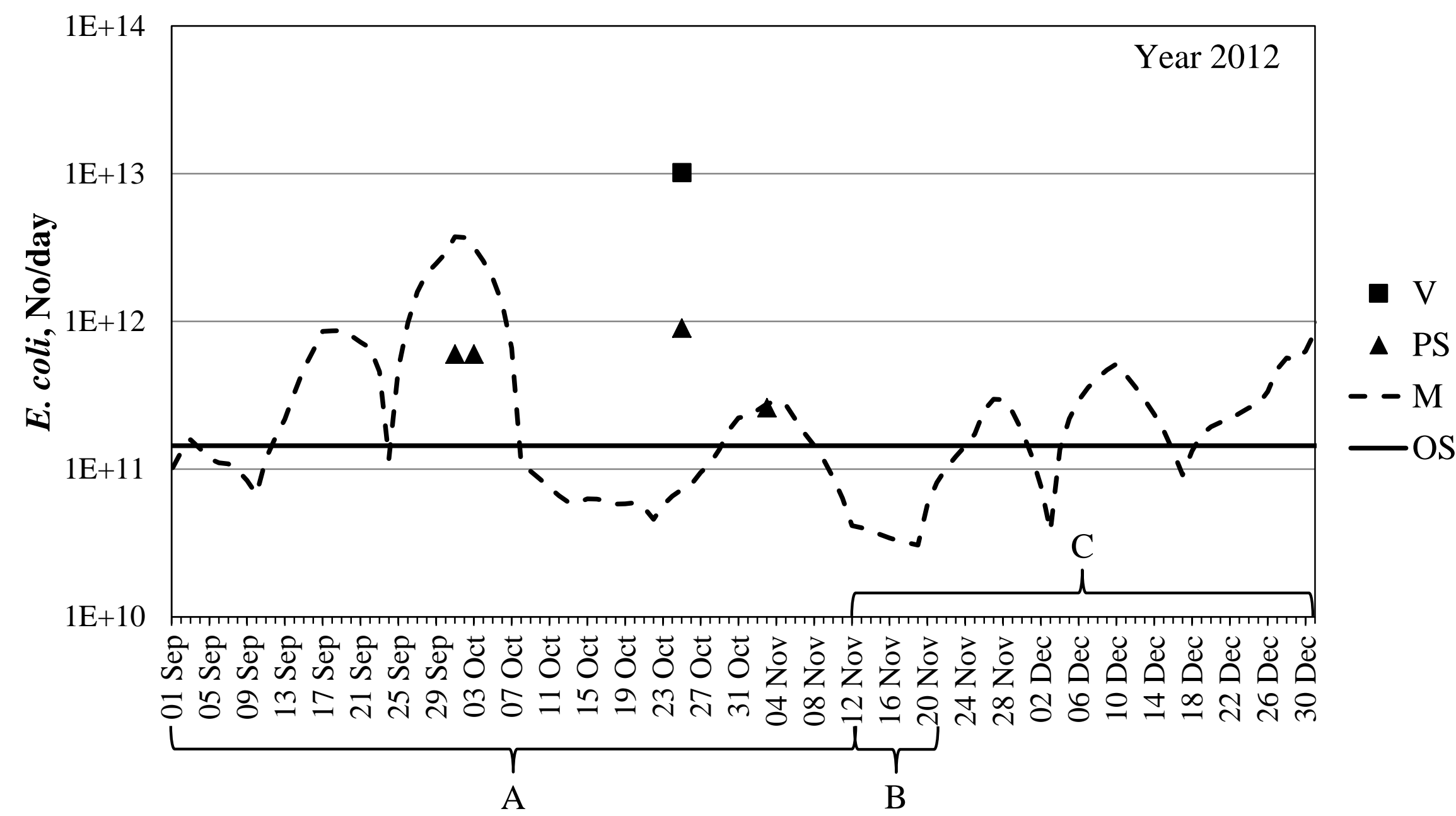

Figure 2 E. coli load to Lake Rådasjön and simulated periods. The contamination sources are: the river Mölndalsån (M), the on-site sewage treatment systems (OS), the stream Vällbäcken (V) and the Pixbo Päls pumping station (PS). (A) and (C) represent the periods for the hindcast simulations, (B) represents the period for the forecast simulation. 


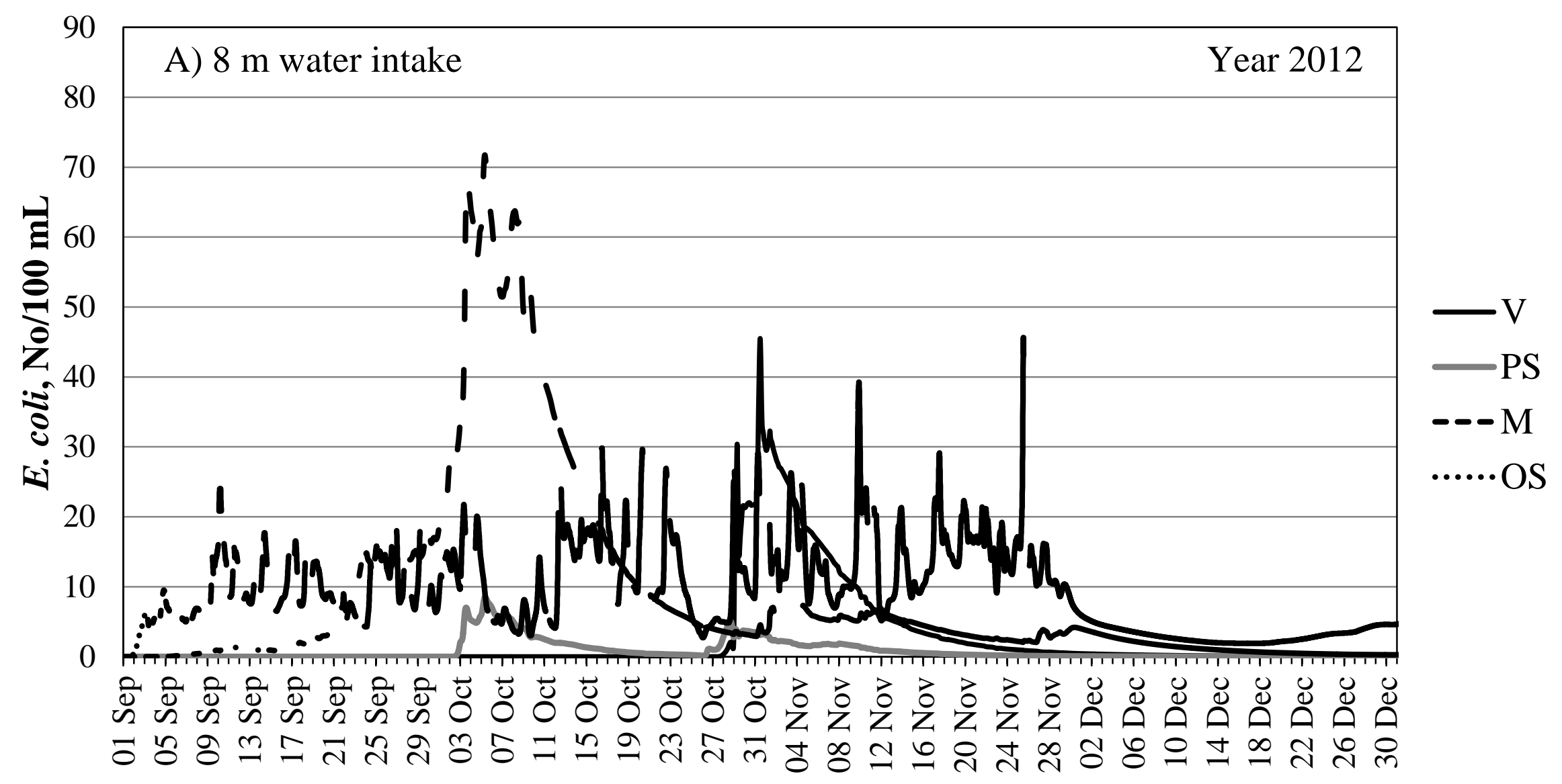




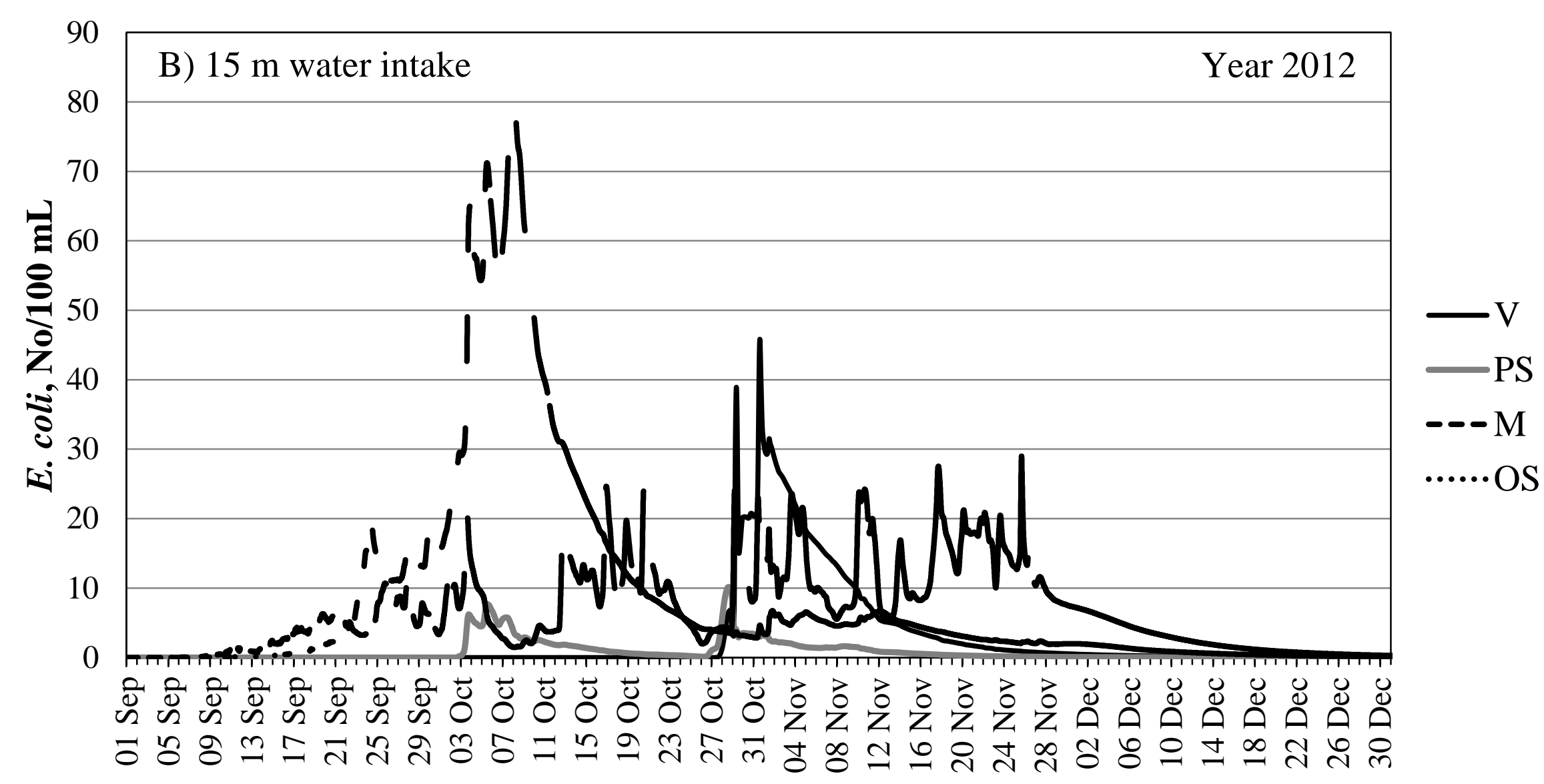

Figure 3 Modelling results: the contribution from the different contamination sources (V - the stream Vällbäcken, PS - the pumping station Pixbo Päls, M - the river Mölndalsån, OS - the on-site sewage treatment systems) to the total E. coli concentrations at the $8 \mathrm{~m}$ (A) and $15 \mathrm{~m}$ (B) water intakes in Lake Rådasjön. 


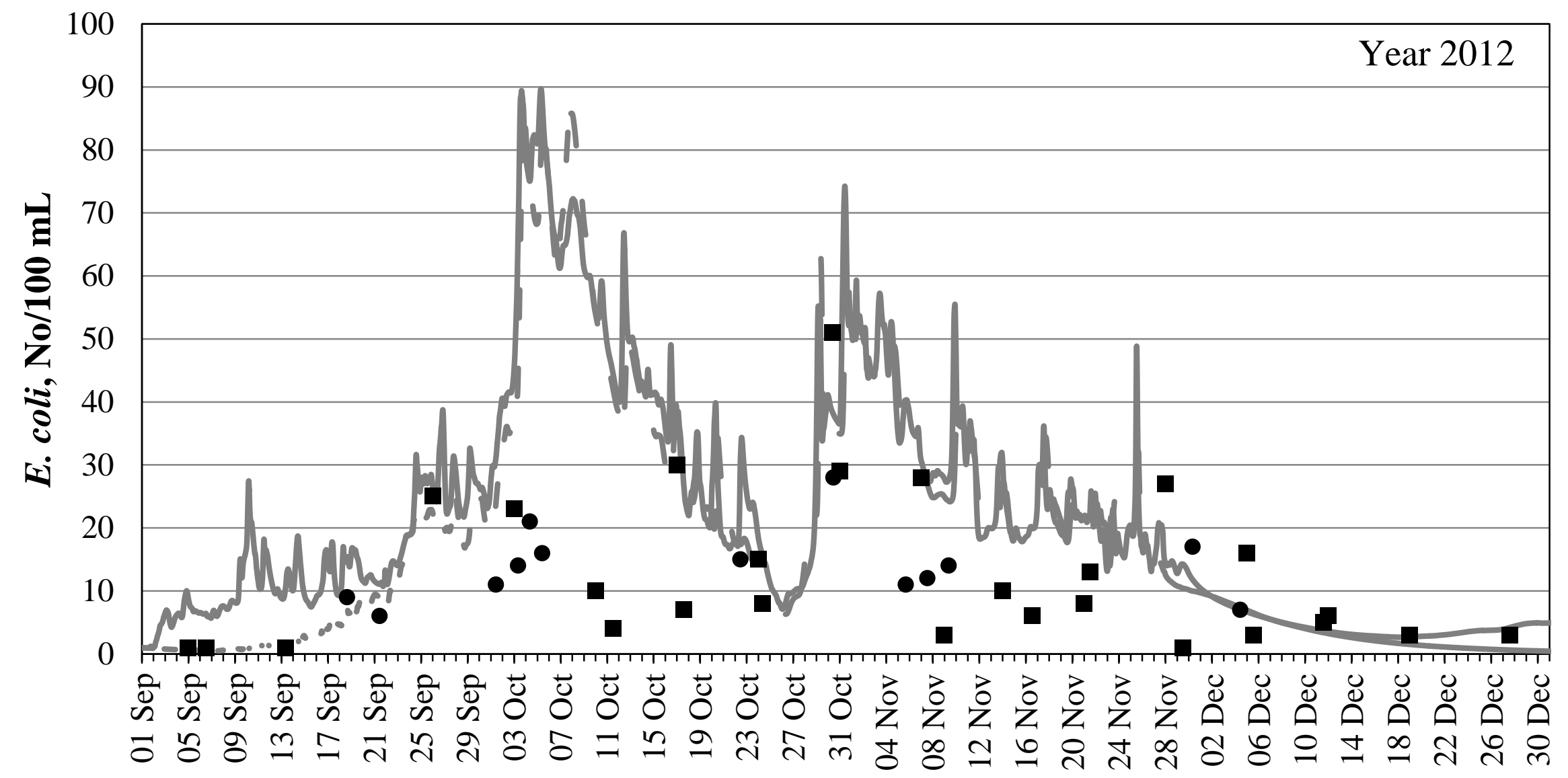

Figure 4 Simulated (continuous and dotted lines) and measured (circles and squares) E. coli concentrations at the $8 \mathrm{~m}$ and $15 \mathrm{~m}$ water intakes, respectively. 

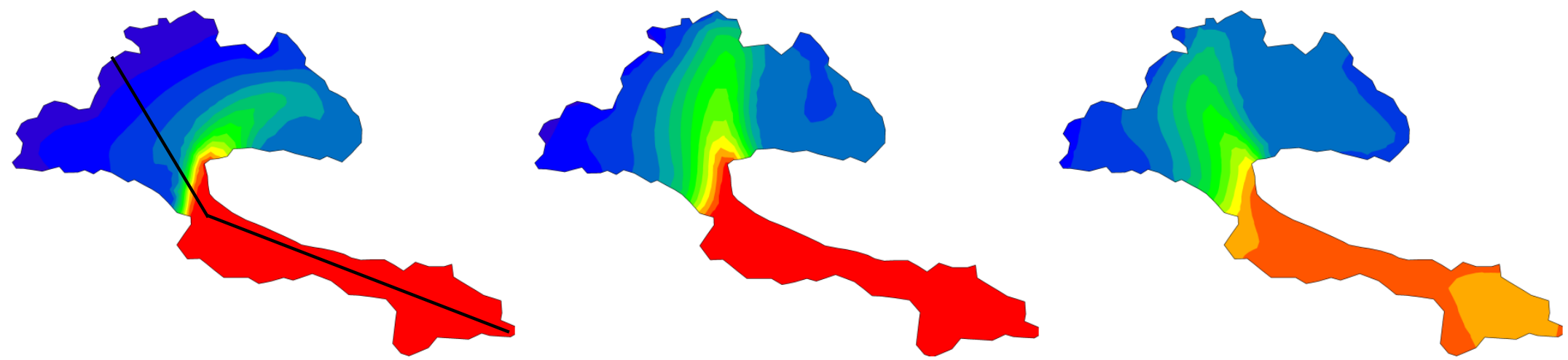

E. coli,

[m]

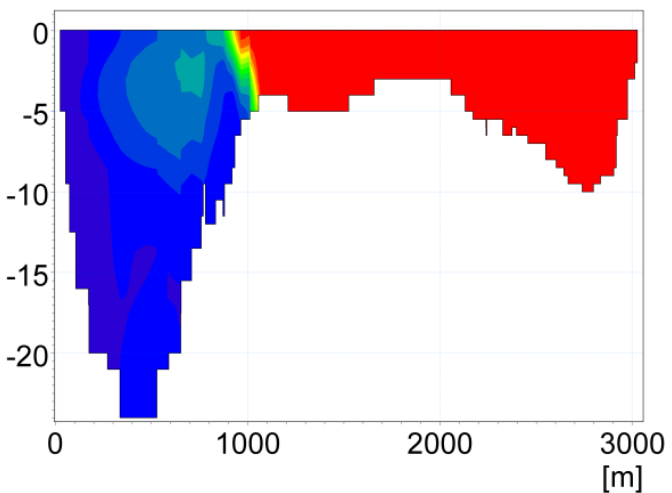

[m]

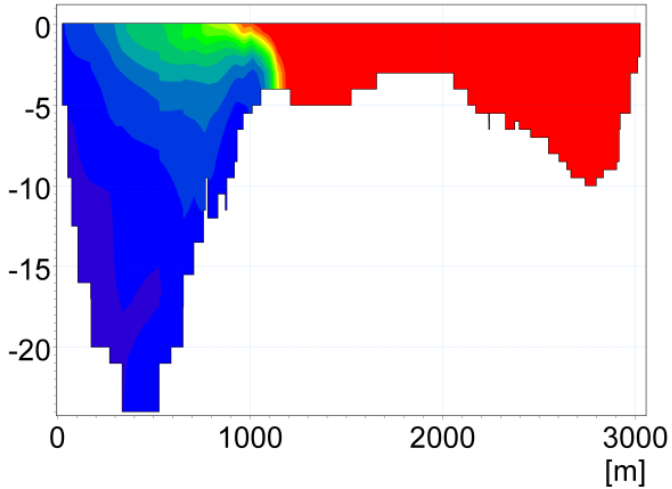

[m]

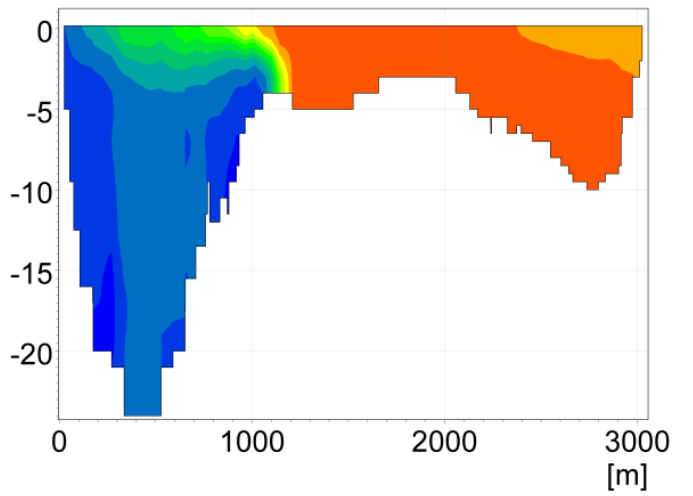

No/100 mL

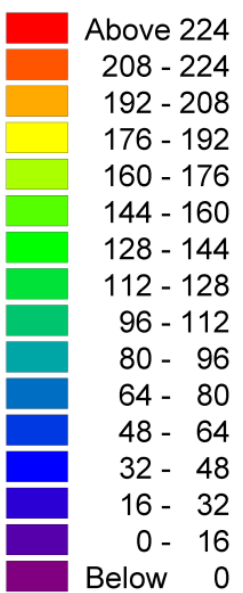

Figure 5 Modelling results: the spread of the faecal contamination (E. coli, No/100 mL) from the river Mölndalsån within Lake Rådasjön on 2, 3 and 4 October 2012. Top and bottom rows represent horizontal and cross-section views, respectively. The approximate location of the crosssection is shown in the top left figure. 


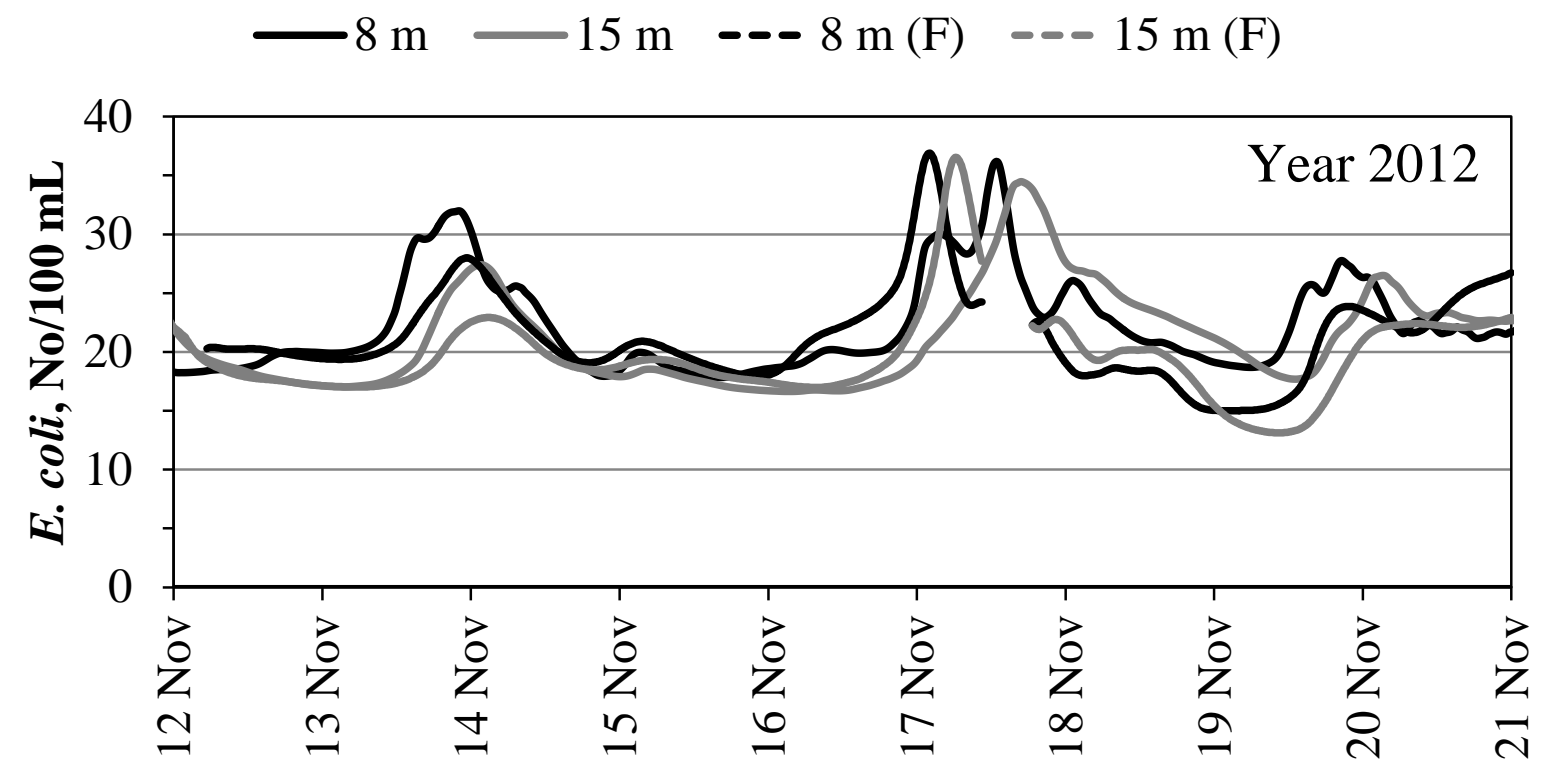

Figure 6 Modelling results: the $E$. coli concentrations at the $8 \mathrm{~m}$ and $15 \mathrm{~m}$ water intakes simulated using the observed input data (" $8 \mathrm{~m}$ " and " $15 \mathrm{~m}$ ", respectively) and the forecast input data (“8 $\mathrm{m}(\mathrm{F})$ ” and “15 $\mathrm{m}(\mathrm{F})$ ”, respectively).

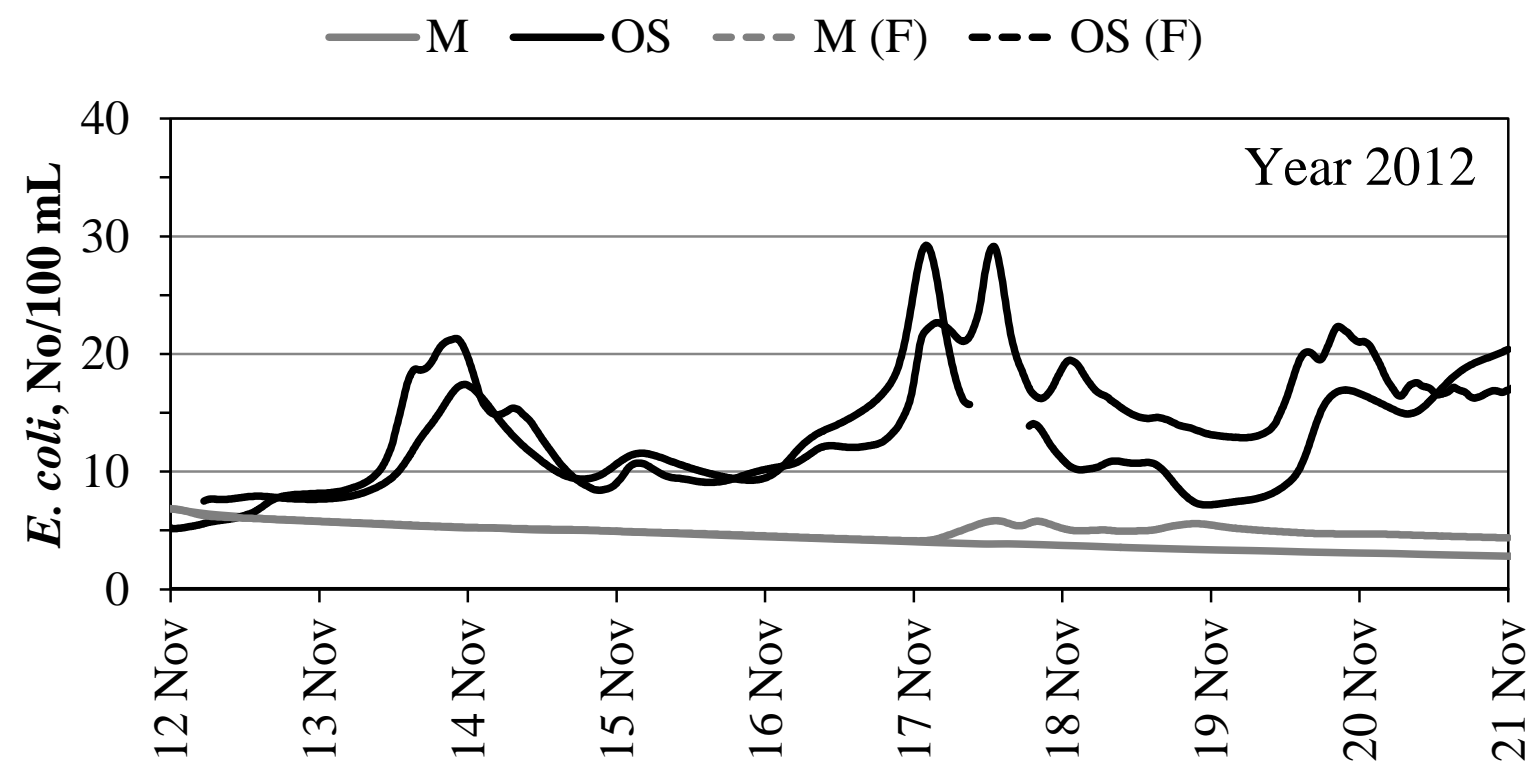

Figure 7 Modelling results: the contributions to the $E$. coli concentrations at the $8 \mathrm{~m}$ water intake from the on-site sewage treatment systems and the river Mölndalsån simulated using the observed input data ("M" and "OS", respectively) and the forecast data ("M (F)" and "OS (F)”, respectively). 
— wind speed $\quad$--- wind speed (F)

— wind direction $\quad \ldots-$ wind direction $(\mathrm{F})$

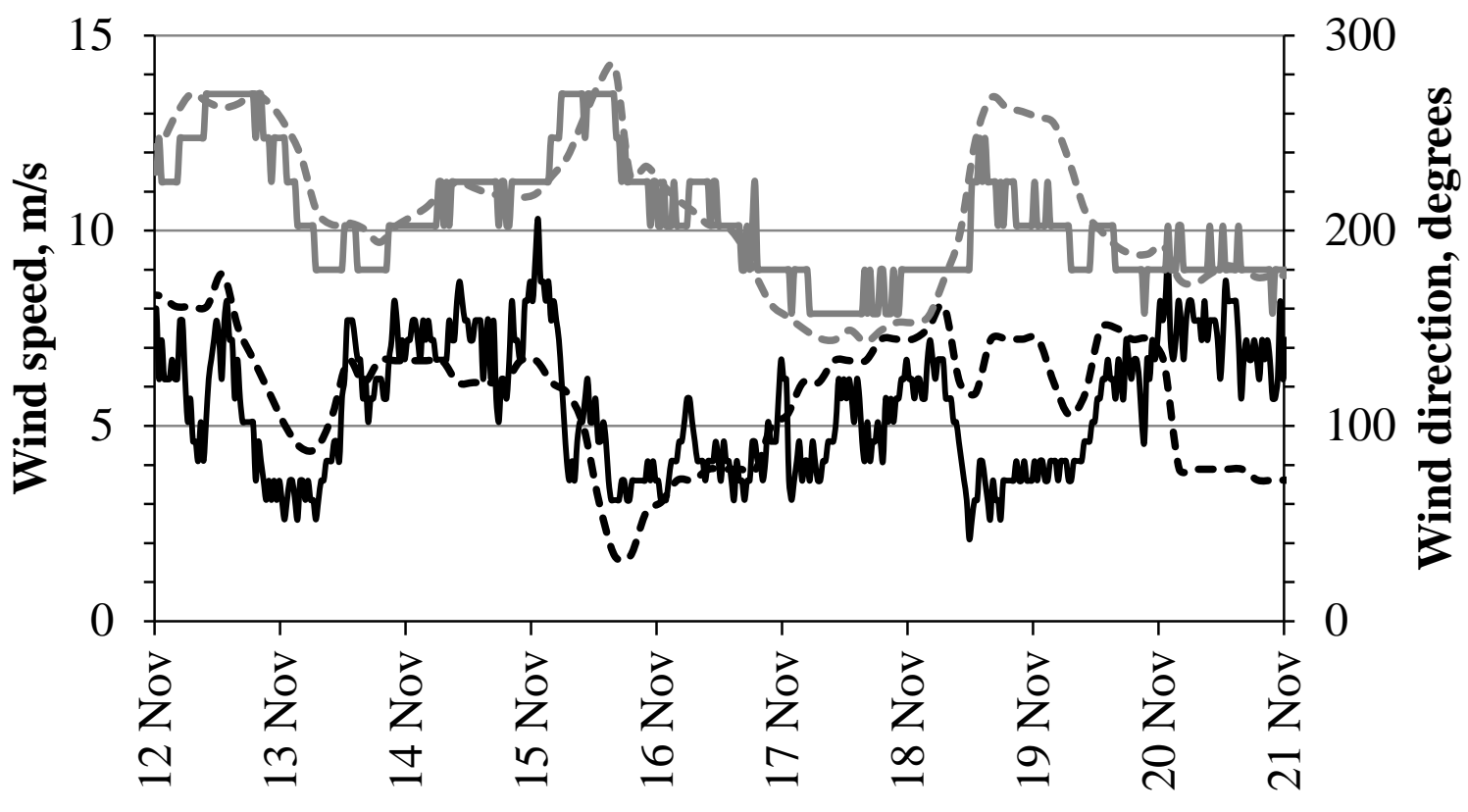

Figure 8 Observed and forecasted (F) wind speed and direction (source: Weather Underground). 